\title{
Assessment of a procedure to determine trace and major elements in atmospheric aerosol
}

\author{
Giuseppa Toscano, ${ }^{a}$ Andrea Gambaro, ${ }^{a b}$ Gabriele Capodaglio, ${ }^{* a b}$ Warren R. L. Cairns ${ }^{b}$ and Paolo Cescon ${ }^{b}$ \\ Received 20th March 2008, Accepted 13th October 2008 \\ First published as an Advance Article on the web 19th November 2008 \\ DOI: $10.1039 / b 804618 b$
}

The determination of trace elements in atmospheric particulate is affected by a number of problems that arise from some critical points such as the blank of the filters, sample heterogeneity and pre-analytical treatments. In the framework of a monitoring campaign conducted in the Venice Lagoon the analytical methodology for the determination of 20 trace elements (Al, As, Ca, Cd, Co, Cr, Cs, Cu, $\mathrm{Fe}, \mathrm{K}, \mathrm{Li}, \mathrm{Mg}, \mathrm{Mn}, \mathrm{Na}, \mathrm{Ni}, \mathrm{Pb}, \mathrm{Rb}, \mathrm{Sr}, \mathrm{V}, \mathrm{Zn}$ ) in atmospheric particulate samples by inductively coupled plasma quadrupole mass spectroscopy (ICP-QMS) has been optimized taking into account the individual critical points. Tests were carried out to estimate the blank contributions, and minimize the detection limit (LOD), measurements were also carried out to evaluate the accuracy and the repeatability. To obtain a complete dissolution of aerosol dust material and good recoveries of the elements, the acid mixture and the microwave assisted digestion program were optimized. The blank contributions from membrane filter manipulation and transportation prior to exposure were tested for the slotted and back filters by placing them on the sampling device for some minutes without air flowing to obtain field blanks (FBs). The contribution to the blank values of passive deposition and by contact with the samplers (quoted as campaign blanks, CBs) was measured by exposing the membranes throughout the sampling session (fifteen days) without any air flow. Instrumental ICP-QMS parameters were optimized and calibration curve intervals were selected on the basis of the necessity of simultaneous determination of the elements present at different levels of concentration. The limits of detection for each elements and the investigated method were suitable to determine the 20 elements reported above in the atmospheric aerosol fractionated in 6 classes ranging between 10 to $0.49 \mu \mathrm{m}$. It allows the determination of trace elements in aerosol in a large range of concentrations that can be observed in areas characterized by remarkable variability and regions with different levels of contamination.

\section{Introduction}

In the last few years much attention has been given to the evaluation of the elemental content of airborne particulate matter due their detrimental effects on human health. Many epidemiological studies have revealed that the degree of adverse respiratory effects depends on the physical and chemical properties of atmospheric aerosol. ${ }^{1-3}$ The particulate matter with an aerodynamic diameter $<10 \mu \mathrm{m}$ (PM10) constitutes the inhalable fraction of aerosol while the particulate matter with an aerodynamic diameter $<2.5 \mu \mathrm{m}$ (PM2.5) could have more serious toxic effects as it constitutes the respirable fraction of the aerosol. Under this framework, European Commission (EC) legislation requires that member states monitor the PM10 and the lead concentration in atmosphere. ${ }^{4}$ Furthermore the EC has recently proposed the monitoring of other toxic elements such as arsenic, cadmium and nickel in atmospheric particulate. ${ }^{5}$

\footnotetext{
${ }^{a}$ Dept. Environmental Sciences, University Ca' Foscari, Dorsoduro, 2137, Venice, Italy.E-mail: capoda@unive.it; Fax: +390412348549

${ }^{b}$ Inst. for the Dynamics of Environmental Processes-CNR, Dorsoduro, 2137, Venice, Italy
}

Since the atmospheric particulate samples are often constituted of minute quantities of dust (fractions of milligrams) collected onto large cellulose filters, as such total sample digestion is widely used for trace element analysis. Various methods using microwave-assisted digestion with different acid mixtures and different heating programs are described in the literature. $^{6-9}$ Yet in the total digestion of aerosol samples, elements contained as impurities in the cellulose material as well as the large amounts of chemicals required could give high blank levels and matrix effects during analysis. Therefore a careful quality control and optimisation of the analytical procedure is indispensable.

The objectives of the present study were to develop a suitable methodology for sampling and for the quantitative determination of trace elements in atmospheric particulate with an accurate blank control, adequate detection limits, recoveries, accuracy and repeatability. The analytical methodology was then used to study the PM10 composition in relation to the content of $\mathrm{Al}$, As, $\mathrm{Ca}, \mathrm{Cd}, \mathrm{Co}, \mathrm{Cr}, \mathrm{Cs}, \mathrm{Cu}, \mathrm{Fe}, \mathrm{K}, \mathrm{Li}, \mathrm{Mg}, \mathrm{Mn}, \mathrm{Na}, \mathrm{Ni}, \mathrm{Pb}, \mathrm{Rb}, \mathrm{Sr}, \mathrm{V}$ and $\mathrm{Zn}$ in the aerosol of some sites of the Venice area with different anthropic influences.

Because of the significant differences between the local sources, we expect a large variability for elements at the trace level; 
therefore the analytical methodology will be used to detect an extended interval of concentrations.

\section{Materials and methods}

Size-fractionated PM10 aerosol samples were collected by brushless high volume samplers (Tisch Environmental Inc., Village of Cleves, Ohio, USA) equipped with a six-stage cascade impactor separating particles in the following dimensional aerodynamic defined classes: $10-7.2 \mathrm{~mm}, 7.2-3 \mathrm{~mm}, 3-1.5 \mathrm{~mm}$, $1.5-0.95 \mathrm{~mm}, 0.95-0.49 \mathrm{~mm},<0.49 \mathrm{~mm}$. Slotted cellulose filters $(14 \times 15 \mathrm{~cm})$ were used to collect the first five fractions and a cellulose filter paper (Whatman grade 41, $20 \times 25 \mathrm{~cm}$ ) was used as a back filter at the end of impactor outlet to inertially collect particles of size $<0.49 \mathrm{~mm}$, the operating flow was $1.13 \mathrm{~m}^{3} \mathrm{~min}^{-1}$.

Aerosol sampling was carried out over four campaigns from March 2002 to June 2003 at four sites in the Venice area. Sampling sites, as well wind direction and speed were chosen in order to evaluate the composition of the inorganic pollutants in areas affected by different sources (Fig 1). Marine and "long range" sources were monitored at site 2 .

("P. Sabbioni" station, lat. $45^{\circ} 25^{\prime} 21.8^{\prime \prime}$ N, long. $12^{\circ} 26^{\prime} 12.2^{\prime \prime}$ E), located on the Northern inlet of the lagoon on the light tower when winds were blowing from the south-east. Aerosol from urban and industrial sources were collected at site 1 ("Moranzani" station, lat. $45^{\circ} 25^{\prime} 38.5^{\prime \prime} \mathrm{N}$, long. $12^{\circ} 12^{\prime} 47.6^{\prime \prime} \mathrm{E}$ ) located south of the Mestre urban area and the Porto Marghera industrial area at site 4 ("Tessera" station, lat. $45^{\circ} 29^{\prime} 37.9^{\prime \prime} \mathrm{N}$, long. $12^{\circ} 19^{\prime} 27.2^{\prime \prime}$ E), located close the Venice Airport when winds were blowing from north-east. Aerosol less affected by local sources was sampled at site 3 located on Monte Grande in the Euganei Hills, a wooded area at $460 \mathrm{~m}$ above sea level and $50 \mathrm{Km}$ from Venice ("Teolo" station, lat. $45^{\circ} 21^{\prime} 43.0^{\prime \prime} \mathrm{N}$ long. $11^{\circ} 40^{\prime} 22.4^{\prime \prime} \mathrm{E}$ ), when wind blew from the north-east. For all the sites aerosol samples were taken when winds blew at a speed greater than $1 \mathrm{~m} \mathrm{~s}^{-1}$. The sampling time was variable as a function of metereological characteristics, therefore the gathered volume of each sample was changeable, it ranged between $500 \mathrm{~m}^{3}$ to $12000 \mathrm{~m}^{3}$.

\section{Filter and vessels cleaning}

All the analytical procedures (cleaning of filters and all plastic items, filter weighing, sample treatment, preparation of standard solutions) were performed under a laminar flow clean area in a class 100 clean chemistry laboratory. Ultrapure water was obtained from a purification system (PURELAB ULTRA from Elga Labwater/VWS - UK Ltd) and suprapure grade reagents $\left(\mathrm{HCl}\right.$ and $\mathrm{HNO}_{3}$ Merck) were used for all cleaning procedures.

Preliminary analysis carried out on untreated filters showed an extremely variable trace metal content, e.g. the content (SD) in $\mu \mathrm{g} /$ filter of $\mathrm{Al}, \mathrm{Ca} \mathrm{Cd}, \mathrm{Cu}, \mathrm{V}$ and $\mathrm{Zn}$ were 8(3), 23(21), $0.071(0.004), 0.20(0.04), 2.3(0.1)$ and $2.0(1.8)$ respectively. Therefore the filters before use were washed by $\mathrm{HCl}$ suprapure grade diluted 1:100 by ultrapure water and rinsed with ultrapure water, the procedure was repeated then the membranes were dried at room temperature in a class 100 laminar flow area. The procedure reduced the content for some elements of about one order of magnitude and averall increase significantly the repeatability of blank measurement. All filters were conditioned for $24 \mathrm{~h}$ at a temperature of $20^{\circ} \pm 5^{\circ} \mathrm{C}$ and a relative humidity of $30 \pm 5 \%$ and were then weighed by a balance with $0.01 \mathrm{mg}$ precision (CP225D Sartorious). Filter weighings were repeated at least three times to assess aerosol masses $\geq 5 \mathrm{mg}$ with a standard deviation of $5-10 \%$. The slotted filters were cut into 4 equal sections and the backup filters were cut into 6 equal sections,

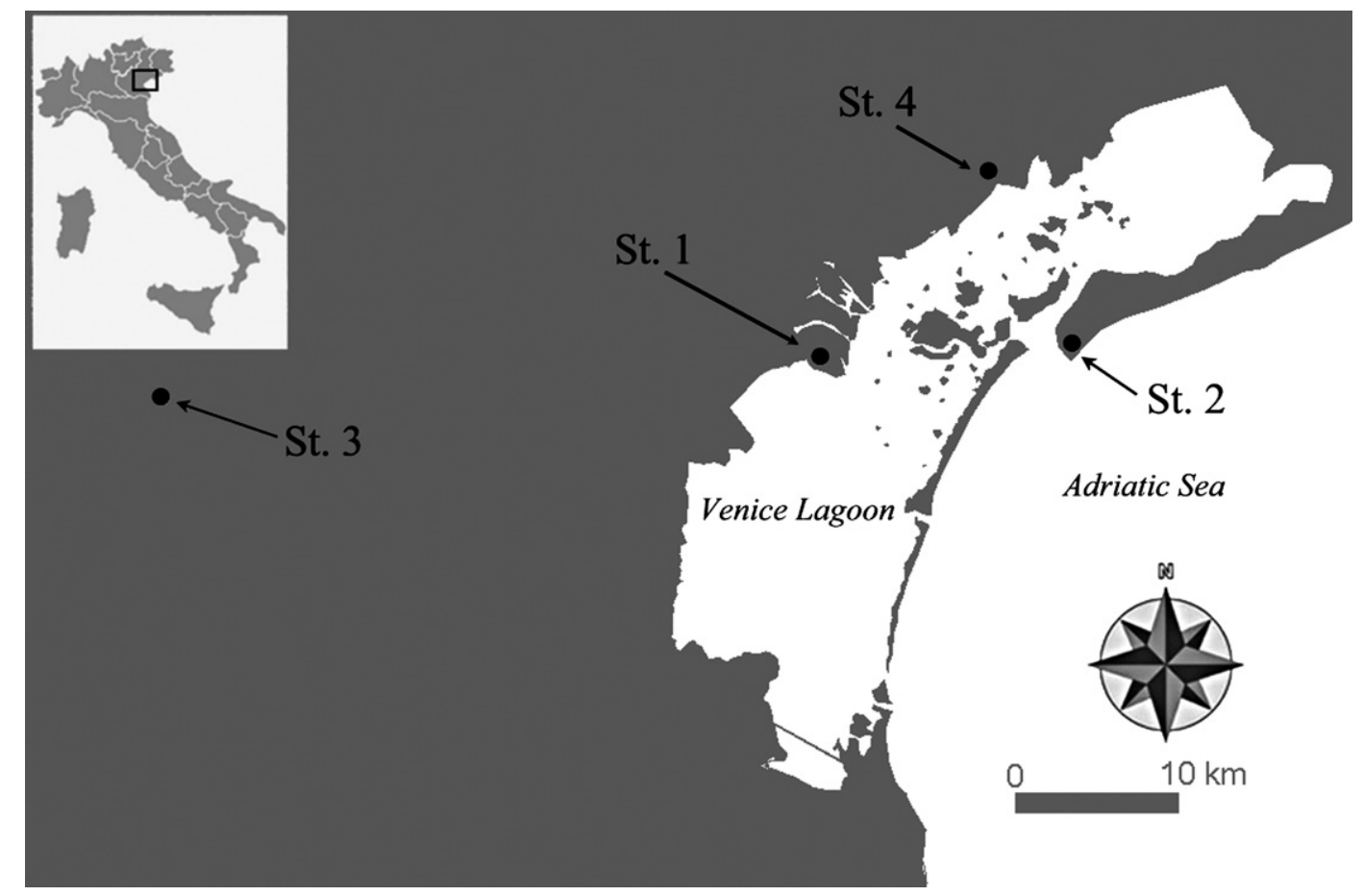

Fig. 1 Sampling sites in the Venice Lagoon area. 
using a polyethylene cutter. The aerosol samples were then closed in washed petri dishes inside plastic bags and stored at $-20{ }^{\circ} \mathrm{C}$ until analysis. Acid cleaned low density polyethylene (LPDE) bottles were used to store the digested samples. Blank filters was washed, dried and weighed following the same analytical protocol used for the sample filters.

\section{Sample treatment and procedure}

The sample digestions were carried out in a microwave oven (Milestone model Ethos 1600) provided with a ten places rotor (HPR 1000/10S) and $100 \mathrm{ml}$ TMF (tretrafluoromethoxil) vessels. Reagents used for sample digestion were ultra pure grade (Ultrapure $\mathrm{HCl}, \mathrm{HNO}_{3}$ and $\mathrm{HF}$ supplied from Romil Ltd Cambridge).

Before sample digestion the TMF vessels were filled with $10 \mathrm{ml}$ supra pure $67-69 \% \mathrm{HNO}_{3}$ and cleaned with a three step digestion programme (step 1: 5 min at $300 \mathrm{~W}$; step 2: 5 min at $0 \mathrm{~W}$; step 3: $5 \mathrm{~min}$ at $400 \mathrm{~W}$ ). After digestion the solutions were diluted to a final volume of $25 \mathrm{ml}$ with ultrapure water in acid cleaned LPDE bottles for the determination of trace elements by ICP-QMS. A reagent blank, composed of the same amounts of chemicals used in the sample digestion, was included in each sample digestion batch to monitor the cleanliness of microwave digestion and sample handling processes during digestion.

\section{Instrumentation and quantification}

$\mathrm{Al}, \mathrm{As}, \mathrm{Ca}, \mathrm{Cd}, \mathrm{Co}, \mathrm{Cr}, \mathrm{Cs}, \mathrm{Cu}, \mathrm{Fe}, \mathrm{K}, \mathrm{Li}, \mathrm{Mg}, \mathrm{Mn}, \mathrm{Na}, \mathrm{Ni}, \mathrm{Pb}$, $\mathrm{Rb}, \mathrm{Sr}, \mathrm{V}$, and $\mathrm{Zn}$ were determined by inductively coupled quadrupole mass spectroscopy (Agilent model 7500) equipped with a double pass spray chamber in PFA fitted with the Agilent V-groove nebulizer and a torch with a ceramic injector tube, resistant to hydrofluoric acid.

Prior to use the ICP-QMS spectrometer was tuned to obtain $\mathrm{CeO}^{+} / \mathrm{Ce}^{+}$ratio $<0.5 \%$ and $\mathrm{Ce}^{2+} / \mathrm{Ce}^{+}$ratio $<2 \%{ }^{10}$ with the sample introduction system in place. The carrier gas flow rate was optimised to maximize the sensitivity for ${ }^{7} \mathrm{Li},{ }^{89} \mathrm{Y}$, and ${ }^{205} \mathrm{Tl}$ and minimize the $\mathrm{CeO}^{+}$and $\mathrm{Ce}^{2+}$ signal. The best signal to noise ratio

Table 1 Instrumental conditions and measurement parameters for the Agilent 7500 inductively coupled plasma quadrupole mass spectrometer

RF power

Spray chamber temperature (S/C)

Carrier gas flow rates

Ion sampling depth

Selected isotopes

Sample uptake rate

Washing time

Take up time

Integration time per point

Number acquisition points per peak was found to be between a flow rate of 1.0 and $1.2 \mathrm{~L} \mathrm{~min}^{-1}$. Since the determined elements are present in aerosol samples at very different concentrations, differentiated integration times (see Table 1) were used to optimise the instrumental sensitivities for each element.

Quantification was performed using matrix-matched calibration curves prepared by using multi-element standard solutions for $\mathrm{As}, \mathrm{Cd}, \mathrm{Co}, \mathrm{Cr}, \mathrm{Cs}, \mathrm{Cu}, \mathrm{Li}, \mathrm{Mn}, \mathrm{Ni}, \mathrm{Pb}, \mathrm{Rb}, \mathrm{Sr}, \mathrm{V}, \mathrm{Zn}$, and by single element standard solutions for $\mathrm{Al}, \mathrm{Ca}, \mathrm{Fe}, \mathrm{K}, \mathrm{Mg}$ and $\mathrm{Na}$. Every analysis cycle calibration curve was prepared using one blank sample where 11 additions were carried out to cover the entire concentration range of elements in the aerosol samples. The following range of concentrations were used: 0.005-200 $\mu \mathrm{g}$ $\mathrm{L}^{-1}$ for $\mathrm{As}, \mathrm{Cd}, \mathrm{Co}, \mathrm{Cr}, \mathrm{Cs}, \mathrm{Cu}, \mathrm{Li}, \mathrm{Mn}, \mathrm{Ni}, \mathrm{Pb}, \mathrm{Rb}, \mathrm{Sr}, \mathrm{V}, \mathrm{Zn}$, and $100-1000 \mu \mathrm{g} \mathrm{L}^{-1}$ for Al, Ca, Fe, K, Mg and Na. A $100 \mu \mathrm{g} \mathrm{L}^{-1}$ Os and $\mathrm{Ru}$ solution was added on line using a T-piece and was used as an internal standard during calibration and sample analysis. Multi-element standard solution of metals $\left(10 \mathrm{mg} \mathrm{L}^{-1}\right)$ were supplied from Ultra Scientific (North Kingstown, RI, USA). Single-element standard solutions were supplied from SPEX CertiPrep. INC. Metuchen (Os and $\mathrm{Ru}, 10 \mathrm{mg} \mathrm{L}^{-1}$ ) and from Ultra Scientific (Al, Ca, Fe, K, Mg, Na $1000 \mathrm{mg} \mathrm{L}^{-1}$ ). For each sampling campaign the blank concentration was measured and used to correct the concentration measured in the dissolved filters.

\section{Results and discussion}

\section{Blanks and detection limits}

Several blanks were collected under particular conditions to better evaluate the contributions from handling, exposure and treatment of the filter and to establish baseline concentrations, which were then subtracted from the concentrations of trace elements in the exposed filters.

The contribution to the blank values from filter handling during aerosol sampling was evaluated by keeping the filters in the samplers at the sampling station for a few minutes without any air flowing and then transferring them to a plastic bag without any further exposure. These blanks, defined field blanks (FBs), were then treated and analysed following the procedure applied to the samples.

Since sampling of the aerosol was carried out only when the wind blew in particular conditions the samplers remained inactive for long time periods. To estimate the contribution to the blank values by passive deposition, the filters were kept at the sampling stations for fifteen days without any air flow. These blanks, defined campaign blanks (CBs), were then treated and analysed as the aerosol samples. In order to emphasize the effect of handling during aerosol sampling, measurements of blank concentration of some elements in filters washed and maintained always inside the class 100 clean area were carried out (filter blank).

The amounts of trace metals found in cellulose slotted filters used as filter blanks, field blanks and campaign blanks are presented in Table 2. The values found in FBs and CBs ranged from $0.0006 \mu \mathrm{g} /$ filter of $\mathrm{Cs}$ to $27 \mu \mathrm{g} /$ filter of $\mathrm{K}$ for the campaign blanks and from $0.0006 \mu \mathrm{g} /$ filter of Cs to $11 \mu \mathrm{g} /$ filter of $\mathrm{Na}$ for the field blanks. One anomalous result was obtained 
Table 2 Mean amounts of elements ( $\mu \mathrm{g} /$ filter) and standard deviation (SD) measured in campaign blanks (CBs) and field blanks (FBs) of slotted filters for the whole processes of sampling, treatment and analysis

\begin{tabular}{|c|c|c|c|c|c|c|}
\hline Element & \multicolumn{2}{|c|}{ Campaign blanks } & \multicolumn{2}{|c|}{ Field blanks } & \multicolumn{2}{|c|}{ Filter blank } \\
\hline As & 0.09 & 0.01 & 0.47 & 0.07 & & \\
\hline $\mathrm{Ca}$ & 8 & 2 & 2.6 & 0.7 & & \\
\hline $\mathrm{Cd}$ & 0.006 & 0.0007 & 0.002 & 0.001 & & \\
\hline Co & 0.0045 & 0.0005 & 0.005 & 0.002 & & \\
\hline $\mathrm{Cu}$ & 0.07 & 0.01 & 0.05 & 0.03 & 0.04 & 0.03 \\
\hline $\mathrm{Fe}$ & 5.1 & 0.3 & 3.1 & 0.8 & & \\
\hline K & 27 & 3 & 2.9 & 0.7 & & \\
\hline $\mathrm{Li}$ & 0.004 & 0.001 & 0.013 & 0.003 & & \\
\hline $\mathrm{Mg}$ & 0.8 & 0.2 & 0.5 & 0.1 & & \\
\hline $\mathrm{Mn}$ & 0.04 & 0.01 & 0.05 & 0.02 & 0.007 & 0.005 \\
\hline $\mathrm{Na}$ & 15 & 2 & 11 & 3 & & \\
\hline V & 0.016 & 0.008 & 0.07 & 0.02 & 0.01 & 0.008 \\
\hline $\mathrm{Zn}$ & 1.6 & 0.5 & 0.4 & 0.1 & 0.24 & 0.12 \\
\hline
\end{tabular}

for arsenic, the concentration in the field blank was about five time higher than the campaign blank. The concentrations of elements measured in filter blank were for larger part of element determined significantly lower than FBs and CBs; therefore is evident that handling the membrane for exposition, transport and settling they on the samplers may contribute significantly at the blank concentration. In spite of the long contact of the $\mathrm{CBs}$ with the sampler no positive trend was observed with respect to FBs, therefore the contribution to the trace elements blank from passive deposition and contact with the sampling system is considered as negligible. Since FBs are easier to collect, they were used to quantify the "limit of detection" (LOD), which was calculated as 3 times the standard deviation values of the blank content, an average air volume of $4449 \mathrm{~m}^{3}$ was used to calculate the LOD in term of $\mathrm{ng} \mathrm{m}^{-3} .^{11}$ The FBs average blank values for back filters are presented in Table 3. The amounts found ranged from $0.002 \mu \mathrm{g} /$ filter for Cs to $24 \mu \mathrm{g} /$ filter for $\mathrm{Na}$.

Slotted filters, which have a lower content of cellulose than back filters, show lower blank values (Table 2 and Table 3 ) for the almost all elements so different blank corrections must be used for the first five fractions (slotted filters) and for the final fraction (size $<0.49 \mathrm{~mm}$ ) (back filters).

Comparison with limits of detection previously published shows that our results are comparable with values reported in the literature. The LODs reported by Yang et al. ${ }^{7}$ ranged from 0.015 $\mathrm{ng} \mathrm{m}^{-3}$ for $\mathrm{Cd}$ to $46 \mathrm{ng} \mathrm{m}^{-3}$ for Ca using microwave digestion and ICP-MS analysis. Fernández Álvarez ${ }^{8}$ reported LOD values ranging between $0.025 \mathrm{ng} \mathrm{m}^{-3}$ for As to $0.94 \mathrm{ng} \mathrm{m}^{-3}$ for $\mathrm{Pb}$ using microwave digestion and inductively coupled plasma atomic emission spectroscopy analysis (ICP-AES). Detection limits found by A. A. Karanasiou et al. ${ }^{6}$ range from $0.0004 \mathrm{ng} \mathrm{m}^{-3}$ for $\mathrm{Cd}$ to $4.3 \mathrm{ng} \mathrm{m}^{-3}$ for $\mathrm{Al}$ using microwave digestion and electrothermal atomic absorption spectroscopy analysis (ETAAS).
Table 3 Mean amounts of elements ( $\mu \mathrm{g} /$ filter), standard deviation (SD), limit of detection (LOD $\mathrm{ng} \mathrm{m}^{-3}$ ) estimated by back filter field blanks

\begin{tabular}{llll}
\hline & \multicolumn{2}{l}{ Field blanks } & \\
\cline { 2 - 4 } Element & Mean $^{a}$ & SD $^{b}$ & LOD $^{c}$ \\
\hline $\mathrm{Al}$ & 3 & 1 & 0.7 \\
$\mathrm{As}$ & 0.65 & 0.06 & 0.04 \\
$\mathrm{Ca}$ & 4.5 & 0.8 & 0.5 \\
$\mathrm{Cd}$ & 0.004 & 0.002 & 0.002 \\
$\mathrm{Co}$ & 0.005 & 0.001 & 0.001 \\
$\mathrm{Cr}$ & 0.7 & 0.1 & 0.1 \\
$\mathrm{Cs}$ & 0.002 & 0.001 & 0.001 \\
$\mathrm{Cu}$ & 0.09 & 0.03 & 0.02 \\
$\mathrm{Fe}$ & 3.9 & 0.5 & 0.3 \\
$\mathrm{~K}$ & 4.1 & 0.5 & 0.3 \\
$\mathrm{Li}$ & 0.017 & 0.003 & 0.002 \\
$\mathrm{Mg}$ & 0.9 & 0.3 & 0.2 \\
$\mathrm{Mn}$ & 0.05 & 0.01 & 0.008 \\
$\mathrm{Na}$ & 24 & 1 & 1 \\
$\mathrm{Ni}$ & 0.09 & 0.03 & 0.02 \\
$\mathrm{~Pb}$ & 0.04 & 0.02 & 0.01 \\
$\mathrm{Rb}$ & 0.007 & 0.002 & 0.001 \\
$\mathrm{Sr}$ & 0.015 & 0.008 & 0.006 \\
$\mathrm{~V}$ & 0.09 & 0.02 & 0.02 \\
$\mathrm{Zn}$ & 1.0 & 0.4 & 0.3
\end{tabular}

${ }^{a}$ Mean. ${ }^{b}$ Standard deviation values calculated by 7 independent part of filters at least. ${ }^{c}$ LOD in $\mathrm{ng} \mathrm{m}^{-3}$ was calculated as three times the blank standard deviation and using an average air volume of $4449 \mathrm{~m}^{3}$.

\section{Accuracy and repeatability}

Several microwave digestion programs with different combinations of power and time settings and different reagent mixtures were tried to achieve complete dissolution of the particulate matter. The best recoveries were obtained by the following step program settings of microwave oven: step 1: $10 \mathrm{~min}$ at $250 \mathrm{~W}$; step 2: $1 \mathrm{~min}$ at $0 \mathrm{~W}$; step 3: $20 \mathrm{~min}$ at $400 \mathrm{~W}$; step 4: $2 \mathrm{~min}$ at 
$0 \mathrm{~W}$; step 5: $20 \mathrm{~min}$ at $500 \mathrm{~W}$, step 6: 2 min at $0 \mathrm{~W}$; step 7: 3 min at $650 \mathrm{~W}$ and two acid mixtures (a) and (b):

(a) $1.5 \mathrm{ml}$ ultra pure water, $5 \mathrm{ml} \mathrm{HNO}_{3}$ and $1 \mathrm{ml} \mathrm{HF}$ (Romil Ultrapure acids);

(b) $1.5 \mathrm{ml}$ ultra pure water, $5 \mathrm{ml} \mathrm{HNO}_{3}, 1 \mathrm{ml} \mathrm{HF}$ and $0.5 \mathrm{ml}$ $\mathrm{HCl}$ (Romil Ultrapure acids).

In order to validate the microwave digestion methods, portions of $1 / 6$ of a blank back filter were loaded with about $10 \mathrm{mg}$ of Standard Urban Dust Reference Material (NIST, SRM-1648). The reagents were added and the filter and reference material were digested following the selected program settings, the solution was diluted until a final volume of $25 \mathrm{ml}$ by ultrapure water. The procedure was repeated at least five time using different portions of the filter for each of the reagent mixtures listed above as (a) and (b). As, $\mathrm{Cd}, \mathrm{Cr}, \mathrm{Cu}, \mathrm{Mn}, \mathrm{Ni}, \mathrm{V}$ concentrations were quantified using matrix-matched calibration curves without any dilution of the digested NIST sample. Al, Fe, K, Na, $\mathrm{Pb}$ and $\mathrm{Zn}$ concentrations were quantified after a 1:100 dilution of the digested reference material sample using external calibration curves. Experimental values and certified values are compared in Table 4. For most of the elements satisfactory agreement between the measured and certified values was found using both the reagent mixtures. Recoveries of the elements content, expressed as a percentage of the NIST certified values, ranged from $79 \%$ for $\mathrm{Cr}$ to $120 \%$ for $\mathrm{Zn}$ in samples digested with the $\mathrm{H}_{2} \mathrm{O}, \mathrm{HNO}_{3}$ and $\mathrm{HF}$ mixture and from $84 \%$ for $\mathrm{V}$ to $105 \%$ for $\mathrm{K}$ in sample digested with the $\mathrm{H}_{2} \mathrm{O}, \mathrm{HNO}_{3}, \mathrm{HF}$ and $\mathrm{HCl}$ mixture. Since no significant difference was found for the two reagent mixtures tested, sample digestion without $\mathrm{HCl}$ were preferred to minimize the interference from ${ }^{40} \mathrm{Ar}{ }^{35} \mathrm{Cl}+$ in the determination of As.

Dividing the filters into smal sections was necessary to avoid the overloading microwave vessels due to the large weight of the cellulose filters (from $1.4 \mathrm{~g}$ for slotted filters to $4 \mathrm{~g}$ for back-filters). The back filters were divided into six equal sections and slotted filers were divided into four equal sections. Since only one section was used to assess the sample concentration, the uniformity of atmospheric particulate distribution on the filters was tested by digestion and analysis of different sections of the same aerosol sample. The results obtained for digestion and analysis of four
Table 5 Results $\left(\mathrm{ng} \mathrm{m}^{-3}\right.$ ), mean values and standard deviation (SD) of elemental content in tests of uniformity of aerosol samples. Digestion and analysis were performed on four sections of a sample collected on a back filter $^{a}$

\begin{tabular}{|c|c|c|c|}
\hline Element & $\begin{array}{l}\text { Results } \mathrm{ng} \mathrm{m}^{-3} \text { in } \\
\text { repeatability tests }\end{array}$ & Mean & SD \\
\hline $\mathrm{Al}$ & $31.4,31.1,31.4,32.3$ & 31.5 & 0.5 \\
\hline As & u.d.1. & u.d.1. & u.d.1. \\
\hline $\mathrm{Ca}$ & $14.6,14.9,16.3,16.3$ & 15.5 & 0.9 \\
\hline $\mathrm{Cd}$ & $0.18,0.22,0.23,0.20$ & 0.21 & 0.02 \\
\hline $\mathrm{Co}$ & $\begin{array}{l}0.0095,0.0093,0.0103 \\
\quad 0.0095\end{array}$ & 0.0096 & 0.0004 \\
\hline $\mathrm{Cr}$ & $0.16,0.19,0.19,0.25$ & 0.20 & 0.04 \\
\hline Cs & $\begin{array}{l}0.0107,0.0112,0.0119 \\
\quad 0.0103\end{array}$ & 0.0110 & 0.0007 \\
\hline $\mathrm{Cu}$ & $0.62,0.68,0.74,0.77$ & 0.70 & 0.07 \\
\hline $\mathrm{Fe}$ & $26,28,31,30$ & 29 & 2 \\
\hline $\mathrm{K}$ & $52,61,62,55$ & 58 & 5 \\
\hline $\mathrm{Li}$ & $\begin{array}{l}0.0269,0.0264,0.0272 \\
\quad 0.0272\end{array}$ & 0.0270 & 0.0004 \\
\hline $\mathrm{Mg}$ & $8.1,8.0,8.6,8.5$ & 8.3 & 0.3 \\
\hline $\mathrm{Mn}$ & $0.93,1.02,1.07,1.00$ & 1.01 & 0.06 \\
\hline $\mathrm{Na}$ & $17.6,18.4,17.7,16.7$ & 17.6 & 0.7 \\
\hline $\mathrm{Ni}$ & $0.79,0.97,0.98,0.89$ & 0.91 & 0.09 \\
\hline $\mathrm{Pb}$ & $3.0,3.7,3.8,3.3$ & 3.5 & 0.4 \\
\hline $\mathrm{Rb}$ & $0.14,0.16,0.17,0.15$ & 0.16 & 0.01 \\
\hline $\mathrm{Sr}$ & $0.119,0.127,0.137,0.132$ & 0.129 & 0.008 \\
\hline V & $1.6,1.9,2.0,1.7$ & 1.8 & 0.2 \\
\hline $\mathrm{Zn}$ & $6.3,7.3,7.2,6.9$ & 6.9 & 0.4 \\
\hline
\end{tabular}

sections of a randomly chosen aerosol sample collected on a back filter are reported in Table 5. The relative standard deviations of element concentrations measured for most elements was less than $10 \%$ showing that the sampled atmospheric particulate can be considered uniformly distributed on the filters and that a section of the filter is representative of the entire sample.

\section{Determination of trace elements in the atmospheric aerosol of the Venice Lagoon}

In order to test the methodology to characterize aerosols with remarkable different composition, the procedure was applied to

Table 4 Elemental contents $\left(\mu \mathrm{g} \mathrm{g}^{-1}\right)$ and percent of recovery obtained for the certified urban particulate (NIST 1648), dissolved by microwave-assisted digestion with two different acid mixtures ${ }^{d, e}$

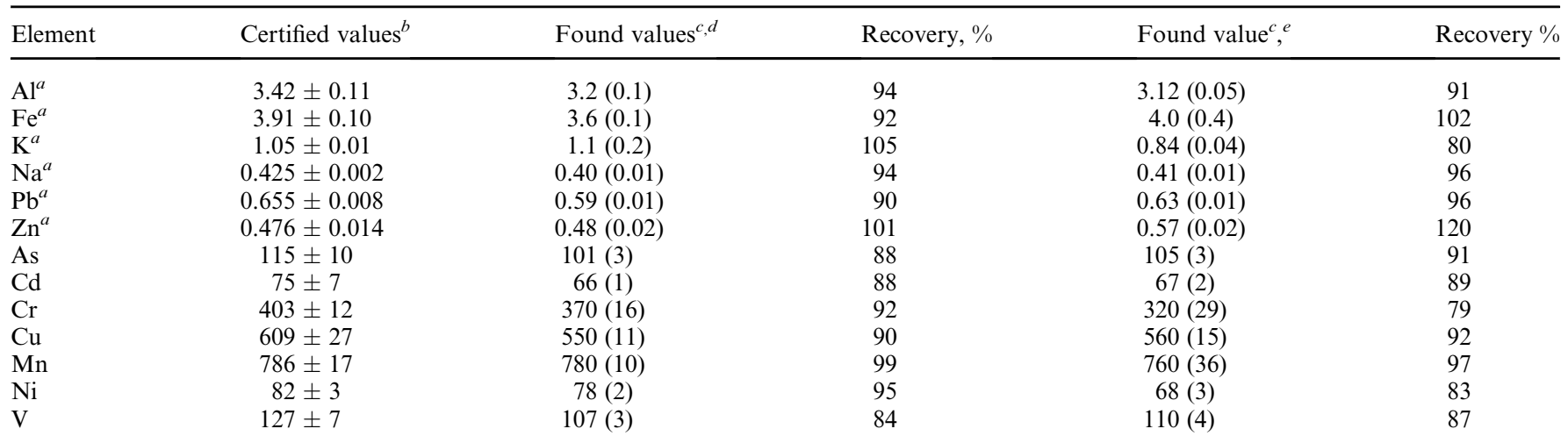

${ }^{a}$ Content in weight percentage (w/w \%). ${ }^{b}$ Average $\pm 95 \%$ tolerance limits. ${ }^{c}$ Average (standard deviation). ${ }^{d}$ Digestion acid mixture: $1.5 \mathrm{ml} \mathrm{H}_{2} \mathrm{O}, 5 \mathrm{ml}$ $\mathrm{HNO}_{3}, 0.5 \mathrm{ml} \mathrm{HCl}, 1 \mathrm{ml} \mathrm{HF}$ (Romil Ultrapure acids). ${ }^{e}$ Digestion acid mixture: $1.5 \mathrm{ml} \mathrm{H}_{2} \mathrm{O}, 5 \mathrm{ml} \mathrm{HNO}, 1 \mathrm{ml} \mathrm{HF}$ (Romil Ultrapure acids). 
determine major and trace element concentrations in the PM10 and to define the distribution between fine (aerodynamic diameter $<3 \mu \mathrm{m}$ ) and coarse particles (aerodynamic diameter $<10 \mu \mathrm{m}$ and $>3 \mu \mathrm{m}$ ) in the atmosphere aerosols collected in areas of the Venice region characterized by airborn particulate of different origin.

Mean values of PM10 and of element concentrations during the entire sampling period are summarized in Table 6. Similar PM10 mean mass concentrations at sites 1,2 and 4 were obtained during the four sampling campaigns $\left(39.3 \mu \mathrm{g} \mathrm{m}^{-3}, 21.0 \mu \mathrm{g} \mathrm{m}^{-3}\right.$ and $34.2 \mu \mathrm{g} \mathrm{m}^{-3}$ respectively), while, a higher median value $\left(56,5 \mu \mathrm{g} \mathrm{m}^{-3}\right)$ was obtained at station 3 (rural area), that was ascribed to occasional fires occuring during the summer season in the neighbouring wood. The results are consistent with those reported for other urban-industrial sites in Europe. Röösli et al. ${ }^{12}$ found in Basel (Central Europe) a mean mass concentration of $28.3 \mu \mathrm{g} \mathrm{m}^{-3}$, Viana et al. ${ }^{13}$ measured at Ghent in west Europe a mass concentration of $28.6 \mu \mathrm{g} \mathrm{m}^{-3}$ during winter 2005 and at Barcelona in the Mediterranean a mass concentration of $34.0 \mu \mathrm{g}$ $\mathrm{m}^{-3}$ during winter 2004. Higher values $\left(78-89 \mu \mathrm{g} \mathrm{m}^{-3}\right)$ are found by Voutsa et al. ${ }^{14}$ at Thelassoniki in Greece during the summer 1997-1998 and by Weckwerth ${ }^{15}\left(54 \mu \mathrm{g} \mathrm{m}^{-3}\right)$ in the atmosphere of Cologne (Germany).

Measured elemental concentrations differ by several orders of magnitude from one metal to another. In relation to their crustal abundance, the highest concentrations are observed for $\mathrm{Al}$ and $\mathrm{Fe}$ at the $\mu \mathrm{g} \mathrm{m}^{-3}$ level, whereas the lowest concentrations, in agreement with their very low crustal abundance, are observed for elements such as Cs, at the sub-ng $\mathrm{m}^{-3}$ level. ${ }^{16}$

The ratio between highest and the lowest concentration detected for trace elements cover an interval ranging between 3 to 15 . Comparison with relevant data from other urban sites shows that the trace element concentrations observed in this study are consistent and close to the ones detected in the aerosol of other cities of the central and northern Europe. Concentrations of $\mathrm{As}, \mathrm{Cd}, \mathrm{Ni}, \mathrm{Pb}$ and $\mathrm{Zn}$ in the PM10 are comparable with those measured in Basel during 97-98, (1 $\mathrm{ng} \mathrm{m}^{-3}$ for As, $1 \mathrm{ng} \mathrm{m}^{-3}$ for $\mathrm{Cd}, 9 \mathrm{ng} \mathrm{m}^{-3}$ for $\mathrm{Ni}, 55 \mathrm{ng} \mathrm{m}^{-3}$ for $\mathrm{Pb}, 84 \mathrm{ng} \mathrm{m}^{-3}$ for $\mathrm{Zn}),{ }^{12}$ in Edinburgh during $1999-2000$ (0.4 $\mathrm{ng} \mathrm{m}^{-3}$ for As, $0.34 \mathrm{ng} \mathrm{m}^{-3}$ for $\mathrm{Cd}, 3.4 \mathrm{ng} \mathrm{m}^{-3}$ for $\mathrm{Ni}, 14.1 \mathrm{ng} \mathrm{m}^{-3}$ for $\mathrm{Pb}, 1.1 \mathrm{ng}$ $\mathrm{m}^{-3}$ for $\mathrm{V}, 13.3 \mathrm{ng} \mathrm{m}^{-3}$ for $\left.\mathrm{Zn}\right)^{17}$ and in Budapest during spring $2002\left(0.99 \mathrm{ng} \mathrm{m}^{-3}\right.$ for As, $27 \mathrm{ng} \mathrm{m}^{-3}$ for $\mathrm{Pb}, 2.8 \mathrm{~V} \mathrm{ng} \mathrm{m}^{-3}, 90 \mathrm{ng}$ $\mathrm{m}^{-3}$ for $\left.\mathrm{Zn}\right) .^{18}$

The particle content and trace element concentration in the fine and coarse fractions are reported in Table 6. The element distribution between fine and coarse is consistent with sources; fine particle concentrations account for $87 \%$ (site 2), $87 \%$ (site 3), $77 \%$ (site 1) and $83 \%$ (site 4 ) of the PM10 particle mass. All the elements that are prevalently originating from anthropogenic sources such as automotive traffic, oil combustion or industrial processes ( $\mathrm{As}, \mathrm{Cd}, \mathrm{Cr}, \mathrm{Ni}, \mathrm{Pb}, \mathrm{V}, \mathrm{Zn}$ ) are essentially associated to the fine particle fraction $(70-95 \%)$. On the other hand, elements such as $\mathrm{Al}$ and $\mathrm{Fe}$ that are mainly from natural sources (soil dust) were almost equally distributed in fine and coarse fractions.

The highest PM10 metal concentration for almost all of the elements was found at station 1 downwind of the large industrial zone of Porto Marghera where the main activities are petrochemical production and refining, iron and steel industries with incineration and thermal plants (fed by fossil fuels). Moreover the site is affected by the vehicular and urban emissions of Mestre.

The concentrations of all the elements, except $\mathrm{Na}$, in the samples collected at site 2, are lower than those measured at St.1 by a factor of $2-4$.

Table 6 Mean particle content $\left(\mu \mathrm{g} \mathrm{m}^{-3}\right)$ and trace element concentration $\left(\mathrm{ng} \mathrm{m}^{-3}\right)$ in $\mathrm{PM}_{10}$, coarse and fine factions of particulate airborne collected in marine, rural, urban and industrial areas of Venice during four campaigns from March 2002 to June 2003

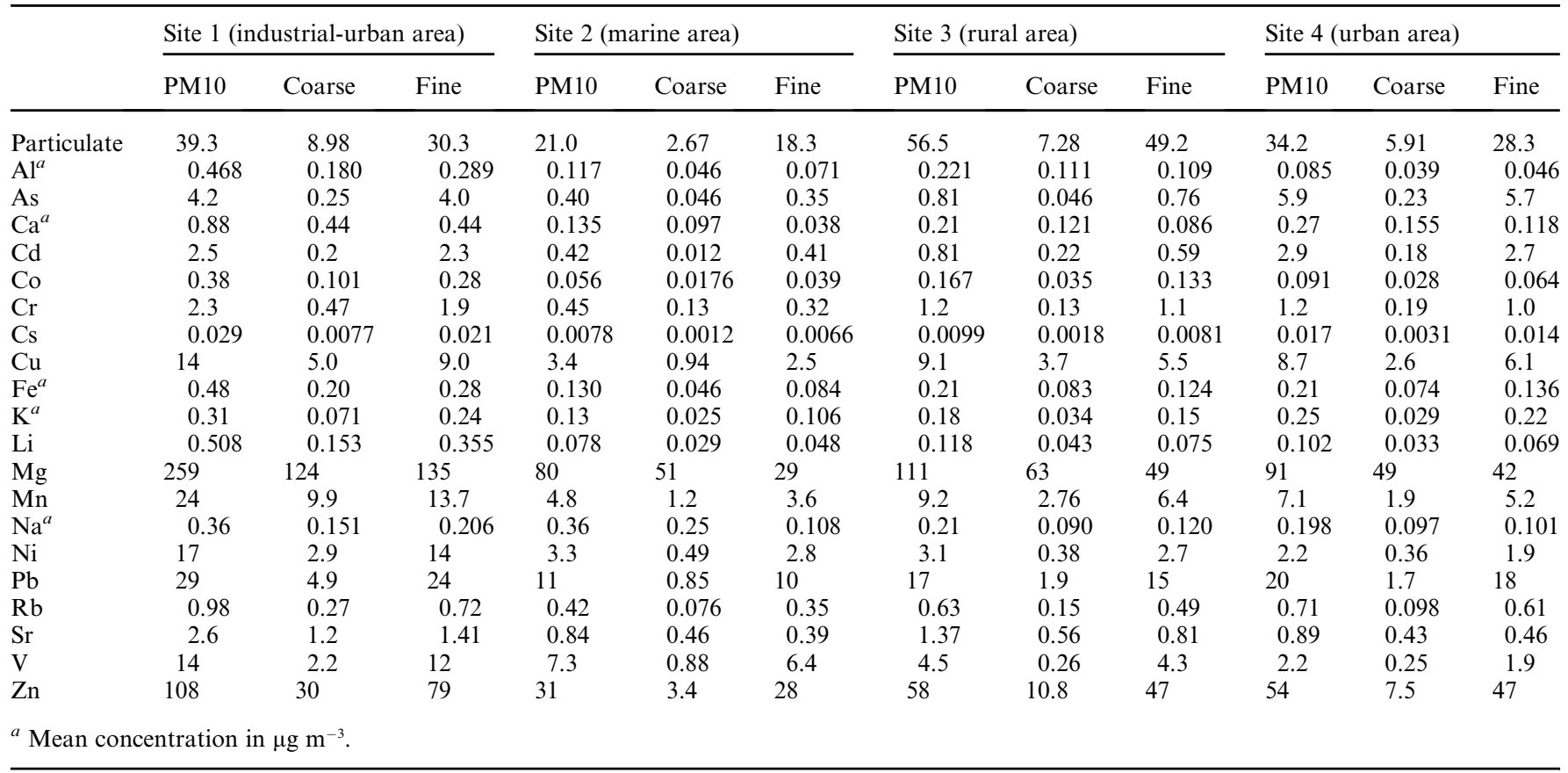




\section{Conclusions}

The proposed method of aerosol sampling, sample microwave digestion and inductively coupled mass spectroscopic analysis allows accurate determination of a large number of elements at trace levels in minute amounts of aerosol samples. The microwave digestion procedure with a simple acid mixture, containing only $\mathrm{HNO}_{3}$ and $\mathrm{HF}$, was validated using the certified reference material NIST SRM 1648 (Urban Particulate Matter). The results show that it is an efficient method for the determination of trace elements in airborne particles with element recoveries always higher than $80 \%$ for all the analysed elements. The contributions of different processes to the blank were evaluated to identify possible sources of sample contamination. The results show that the blank contributions from filter handling and sampling procedures are critical and must be controlled for a correct evaluation of the analytical results. The contribution is significant from the filter handling, transport and settling on the sampling system, while the contributions to the blank values by passive deposition is negligible therefore blank contributions can be evaluated by placing filters on the sampling device at every sampling station for some minutes without any air flow. The measured LODs for the method allow the determination of trace elements in aerosol in the range of concentrations observed in the four areas characterized from aerosol of different origin if the sampled air-volume is $1000 \mathrm{~m}^{3}$ or higher.

\section{Acknowledgements}

This study has been supported by the Consortium for Coordination of Research Activities concerning the Venice Lagoon System (CORILA) within the project "Role of aerosol and secondary pollution in the chemical contamination of the lagoon of Venice". We thank the Ente Zona Marghera and ARPAV for sampling support and V. Zampieri for technical support.

\section{References}

1 N. Englert, Toxicol. Lett., 2004, 149, 235-242.

2 C. A. III Pope, Toxicology, 1996, 111, 149-155.

3 J. Schwartz, D. W. Dockery and L. M. Neas, J. Air Waste Manage. Assoc., 1996, 46, 927-939.

4 Common Position (EC) No. 57/98, 98/C360/04, Official Journal of European Communications C360/99 23 November 1998.

5 Commission of the European Communities, COM (2003) 423 final, 16 July 2003.

6 A. A. Karanasiou, N. S. Thomaidis, K. Eleftheriadis and P. A. Siskos, Talanta, 2005, 65, 1196-1202.

7 K. X. Yang, K. Swami and L. Husain, Spectrochim. Acta B, 2002, 57, $73-84$.

8 F. Fernández Álvarez, M. Ternero Rodríguez, A. J. Fernández Espinosa and A. Gutiérrez Dabán, Anal. Chim. Acta, 2004, 524, $33-$ 40.

9 N. J. Pekney and C. I. Davidson, Anal. Chim. Acta, 2005, 540, 269277.

10 E. McCurdy and D. Potter, Spectroscopy Europe, 2001, 13/3, 14-20.

11 IUPAC, Nomenclature, symbols, units and their usage in spectrochemical analysis II, Spectrochim. Acta B, 1978, 33, 241-245.

12 M. Röösli, G. Theis, N. Künzli, J. Staehelin, P. Mathys, L. Oglesby, M. Camenzind and C. Braun-Fahrländer, Atmos. Environ., 2001, 35, 3701-3713.

13 M. Viana, W. Maenhaut, X. Chi, X. Querol and A. Alastuey, Atmos. Environ., 2007, 41, 315-326.

14 D. Voutsa, C. Samara, T. H. Kouimtzis and K. Ochsenkühn, Atmos. Environ., 2002, 36, 4453-4462.

15 G. Weckwerth, Atmos. Environ, 2001, 35, 5525-5536.

16 K. H. Wedepohl, Geochim. Cosmochim. Acta, 1995, 59, 1217-1232.

17 M. R. Heal, L. R. Hibbs, R. M. Agius and I. J. Beverland, Atmos. Environ., 2005, 39, 1417-1430.

18 I. Salma and W. Maenhaut, Environ. Pollut., 2006, 143, 479-488. 